\title{
Cross-sectional Study on Prevalence of Gastrointestinal Parasitic Infection in Sheep: Comparative Analysis between Agro-climatic Zones of West Bengal, India
}

\author{
Ruma Jas ", Dhananjay Kumar, Soumitra Pandit, Anupam Brahma and Surajit Baidya
}

Department of Veterinary Parasitology, West Bengal University of Animal and Fishery Sciences, 37, Kshudiram Bose Sarani, Kolkata - 700 037, West Bengal, India

*Corresponding author

\section{Keywords}

Agro-climatic

zones,

Gastrointestinal helminths, Intensity, Prevalence, Sheep

Article Info

Accepted:

15 December 2019

Available Online:

20 January 2020

\section{A B S T R A C T}

A comparative cross-sectional study on prevalence of naturally occurring gastrointestinal (g.i.) helminth infection was conducted for five years between the sheep of New Alluvial Zone (NAZ) and Red Laterite Zone (RLZ) of West Bengal, India. Faecal samples of 160 sheep were collected and examined by the standard coprological techniques at monthly interval from each of the agro-climatic zones. The overall prevalence of gastrointestinal helminth was $68.60 \%$ and $68.90 \%$ in sheep of NAZ and RLZ, respectively. Strongyle group of nematodes and Paramphistomes were more prevalent $(\mathrm{P}>0.05)$ in RLZ compared to NAZ. In monsoon the overall prevalence was higher in sheep of RLZ (82\%) compared to NAZ $(76.3 \%)$ whereas in summer the prevalence was significantly $(\mathrm{P}<0.05)$ higher in NAZ (61.5\%) compared to RLZ (55.85\%). The intensity of g.i. nematodes was higher in NAZ (EPG - 584.5) than the RLZ (EPG - 557.58) of West Bengal. Haemonchus contortus was recorded as the predominant parasites of both RLZ (64.8\%) and NAZ (66.4\%). The present study showed no significant $(\mathrm{P}<0.05)$ difference in prevalence of helminthic infection except in few occasions between the NAZ and RLZ of West Bengal. Therefore a common worm control programme can be adopted for the sheep of NAZ and RLZ, West Bengal, India.

\section{Introduction}

India has a vast population of sheep but productivity per animal and thereby economic gain to the farmers is suboptimal due to various factors such as malnutrition, inefficient management, lack of suitable breeding strategies and disease (Adzitey, 2013, Ibrahim et al., 2014). Although sheep suffer from a variety of diseases but their 
habits and rearing practice make them highly prone to g.i. parasitic diseases. Gastrointestinal parasitism caused by different types of helminth parasites is the major constraint for profitable small ruminant production (Jas et al., 2017, Jas and Ghosh, 2009). Parasitic gastroenteritis is generally chronic and subclinical in nature but causes huge economic losses to the farmers as it remains undiagnosed and untreated. Economic losses caused by helminth parasites are mainly due to reduced productive (lower weight gain, lower milk and wool production) and reproductive efficiency and reduced work capacity, cost of treatment and mortality in heavy infection (Fikru et al., 2006).

The epidemiology of gastrointestinal helminths is associated with agro-climatic conditions such as quality and quantity of pasture, temperature, rainfall and humidity of an area and also related to the local husbandry practices. Epidemiological knowledge as well as determination of risk factors for parasite prevalence is prerequisite for planning a control strategy against parasitic diseases in an area. Risk factors are three types (Odoi et al., 2007); parasite factors (prevalence of different species), host factors (genetic resistance, age, sex) and environmental factors (climate, nutrition and management practices).

Comprehensive epidemiological knowledge based on long term studies is not available on g.i. helminths of sheep of NAZ and RLZ of West Bengal. Therefore the present work was conducted to study the cross-sectional prevalence of different types of naturally occurring gastrointestinal parasites in sheep of NAZ and RLZ of West Bengal and all the data obtained in the present study were analyzed statistically both between and within agro-climatic zones to record any significant difference between the two zones.

\section{Materials and Methods}

\section{Study area}

The study was conducted under the mandate of the Indian Council Agricultural Research funded research project entitled 'All India Network Programme on gastrointestinal parasitism'. West Bengal state has been divided into six agro-climatic zones based on homogeneity, rainfall, soil and agricultural practices. Out of the six agro-climatic zones, two zones viz., New Alluvial Zone (NAZ) and Red Laterite Zone (RLZ) were selected during the study period of the project. From each zone four districts were selected and the study was conducted in Nadia, Burdwan, Howrah and Hooghly district of NAZ and in Bankura, Birbhum, Purulia and West Midnapore in RLZ. Two villages from two different blocks were selected from each district and therefore eight different places were selected from each of the agro-climatic zones. The tropical to sub-tropical wet-dry type of climate and reddish brown coloured soil with concentration of iron-aluminium oxides are the characteristics of RLZ and tropical moist sub-humid climate and recent deposits by the river Ganges is the soil type of NAZ. Monthly average temperature, rainfall and humidity of both the zones are comparable and each zone is having ample green grasses, trees and ponds.

\section{Selection of Animals}

In the selected places sheep were reared by the small and marginal farmers. Sheep plays an important role in the sustenance of small and marginal farmers in rural India. Semiintensive system of rearing was practiced in those villages without any routine deworming schedule. Apparently healthy Sheep of either sex and in the age group of 4 months to 2 years old were selected and properly identified by using neck tags, ear-tags or by 
colouring the wools. All the animals were allowed to graze in common pasture area of the village during the day time and in night they were kept in animal house. No other concentrate feed was offered to the animals except the kitchen wastes. The study was continued for five years April, 2012 to March, 2017.

\section{Collection and examination of faecal samples}

Per rectal or when available freshly voided faecal samples were collected from representative number $(n=20)$ of sheep from each of the selected villages and monthly 160 faecal samples were collected from each agroclimatic zone. Faecal samples were collected at monthly interval from April, 2012 to March, 2017 and a total of 19200 faecal samples were collected and examined during the study period.

About $6 \mathrm{gm}$ of faecal sample were collected and about $3 \mathrm{gm}$ of sample was kept in plastic vials (Tarsons, India) containing 10\% formalin and the vials were properly labeled. Rest of the sample was collected in a polythene bags where faecal samples of all the sheep of a particular place were mixed without adding any preservative. The faecal samples were brought to the laboratory for examination following the standard method of sample dispatch.

Faecal samples collected in $10 \%$ formalin were examined by standard sedimentation and floatation technique (Soulsby, 1982) for the presence of any helminthic eggs at monthly interval during the entire study period. The intensity of g.i. nematode infections in terms of faecal egg count (FEC) was measured by estimating the number of nematode eggs per gram of faeces (EPG) following the modified Mc. Master technique (Soulsby, 1982).
Honey-jar coproculture technique (Soulsby, 1982) was adopted for determining the prevalence of different species of Strongyle group of nematodes in each of the agroclimatic zones using the pooled faecal samples collected in the polythene bags. Third stage infective larvae of strongyle group of nematodes were harvested 10 days after the culture and finally procured in distilled water. The percent prevalence of different nematode larvae was determined following the standard guidelines (HMSO, 1971).

\section{Meteorological data}

Daily meteorological data viz., maximum and minimum temperature, relative humidity and rainfall of two agro-climatic zones (NAZ and RLZ) during the year 2012 - 2017 were collected from the Regional Meteorological Station, Kolkata, West Bengal, India. All the data were compiled and presented as monthly average maximum and minimum temperature, average relative humidity and monthly total rainfall in Table 1.

\section{Statistical analysis}

All the data were statistically analyzed (Analyze - Compare Means) for the mean value along with standard error (SE) by Duncan method (One way ANOVA) and the significance ( $p$ value) was recorded at $5 \%$ level $(p<0.05)$ and $1 \%$ level $(p<0.01)$. Data on prevalence of different types of helminth parasites were analyzed to record variation both between and within the agro-climatic zones. The complete statistical analysis was made by Statistical Package for Social Scientists (SPSS), Windows Version 20.0.

\section{Results and Discussion}

\section{Prevalence of gastrointestinal helminthes}

Monthly 160 faecal samples were examined from each of the agro-climatic zones and a 
total 19200 faecal samples were examined during the five years study period. The prevalence of different types of helminths has been presented in Fig. 1.

The prevalence of different types of helminth parasites was $68.76 \%$ in sheep of selected places of West Bengal. No significant $(\mathrm{P}>0.05)$ difference was recorded in overall prevalence of naturally occurring g.i. parasites between the sheep of NAZ (68.60\%) and RLZ $(68.85 \%)$. Strongyle group of nematodes was the predominant parasites in sheep of both the zones with slightly higher $(\mathrm{P}>0.05)$ in sheep of RLZ (63.57\%) than the NAZ (61.91\%). Prevalence of Fasciola, Paramhistome and Moniezia were reported higher $(\mathrm{P}>0.05)$ in sheep of RLZ whereas the prevalence of Strongyloides and Trichuris was recorded slightly higher $(\mathrm{P}>0.05)$ in sheep of NAZ (Fig. 1).

Seasonal variation in prevalence of g.i. helminthes

Seasonal variation in prevalence of different types of helminth parasites was recorded in sheep of both NAZ and RLZ of West Bengal. The prevalence of g.i. helminths varied significantly $(\mathrm{P}<0.05)$ during the three seasons. The overall prevalence of g.i. parasites in sheep was recorded significantly $(\mathrm{P}<0.05)$ highest in monsoon $(79.18 \%)$ followed by winter $(68.43 \%)$ and lowest in summer $(58.68 \%)$ irrespective of different zones of West Bengal (Fig. 2). The seasonal prevalence of different helminth parasites followed the same pattern in both the agroclimatic zones as that of overall prevalence (Fig. 3 \& Fig. 4).

During the summer season the overall prevalence of g.i. helminths was recorded significantly $(\mathrm{P}<0.05)$ higher in sheep of NAZ $(61.5 \%)$ compared to the sheep of RLZ $(55.84 \%)$. The prevalence of Strongyle group of nematodes (78.65\%) and Moniezia $(13.85 \%)$ was found significantly $(\mathrm{P}<0.05)$ higher in sheep of RLZ compared to NAZ (Strongyle - 68.8\%; Moniezia - 10.30\%) during monsoon. In the NAZ the prevalence of Paramphistome was significantly $(\mathrm{P}<0.05)$ higher in monsoon (18\%) compared to summer $(10.05 \%)$ but there was no significant $(\mathrm{P}>0.05)$ difference between the monsoon and winter season (Fig. 3). Whereas, in RLZ (Fig. 4) the prevalence of Paramphistome was significantly $(\mathrm{P}<0.05)$ higher in monsoon $(20.35 \%)$ compared to winter $(15.70 \%)$ and summer $(11.25 \%)$.

\section{Intensity of Strongyle group of nematode infection}

Since the Strongyle group of nematodes $(62.66 \%)$ was recorded as the predominant g.i. parasites, monthly as well as seasonal intensity of infection in terms of faecal egg count were recorded in sheep of both the agro-climatic zones.

The monthly and seasonal intensity of Strongyle group of nematode infection has been presented in Fig. 5 and Fig. 6, respectively. In both the zones highest intensity of infection was recorded in month of September and lowest intensity of infection was observed in the month of May (Fig. 5).

The overall intensity of infection in terms faecal egg count i.e. eggs per gram (EPG) of faeces was slightly higher in sheep of NAZ $(\mathrm{EPG}=584.5)$ compared to RLZ $(\mathrm{EPG}=$ 557.58 ) but this difference in FEC was not statistically significant (Fig. 6). In both the agro-climatic zones the intensity of infection was significantly $(\mathrm{P}<0.05)$ higher in monsoon compared to summer and winter. No significant difference in FEC of sheep was observed between summer and winter seasons of West Bengal. 
Percent prevalence of different species of Strongyle group of nematodes

Strongyle group of nematodes generally consist of different types of g.i. nematode species. Coprocultural examination was done to determine the prevalence of different species Strongyle group of nematodes and the results have been presented in Fig. 7.

Table.1 Overall monthly Meteorological data of two agro-climatic zones of West Bengal during the study period

\begin{tabular}{|c|c|c|c|c|c|c|c|c|}
\hline \multirow{2}{*}{ Months } & \multicolumn{2}{|c|}{$\begin{array}{c}\text { Maximum } \\
\text { Temperature }\left({ }^{\circ} \mathbf{C}\right)\end{array}$} & \multicolumn{2}{c|}{$\begin{array}{c}\text { Minimum } \\
\text { Temperature }\left({ }^{(} \mathbf{C}\right)\end{array}$} & \multicolumn{2}{c|}{$\begin{array}{c}\text { Relative } \\
\text { Humidity }(\%)\end{array}$} & \multicolumn{2}{c|}{$\begin{array}{c}\text { Total Rainfall } \\
(\mathbf{m m})\end{array}$} \\
\cline { 2 - 10 } & $\mathbf{N A Z}$ & $\mathbf{R L Z}$ & $\mathbf{N A Z}$ & $\mathbf{R L Z}$ & $\mathbf{N A Z}$ & $\mathbf{R L Z}$ & $\mathbf{N A Z}$ & $\mathbf{R L Z}$ \\
\hline January & 23.35 & 25.58 & 12.31 & 11.3 & 75.42 & 69.2 & 10.77 & 17.34 \\
\hline February & 27.58 & 30.02 & 16.18 & 14.3 & 71.14 & 59.26 & 17.73 & 12.88 \\
\hline March & 32.7 & 35.4 & 20.07 & 18.98 & 68.13 & 47.28 & 30.28 & 15.8 \\
\hline April & 34.38 & 38.06 & 24.6 & 22.3 & 69.55 & 53.68 & 46.88 & 78.8 \\
\hline May & 36.11 & 38.02 & 26.35 & 24.2 & 70.36 & 65.52 & 99.24 & 130.78 \\
\hline June & 34.15 & 36.2 & 26.51 & 24.64 & 79.97 & 77.24 & 312.97 & 282.72 \\
\hline July & 31.73 & 33.04 & 25.93 & 24.32 & 86.03 & 85.22 & 360.39 & 288.56 \\
\hline August & 32.14 & 32.78 & 26.12 & 24.84 & 84.73 & 87.37 & 233.63 & 330.94 \\
\hline September & 32.16 & 32.76 & 25.76 & 25.2 & 83.66 & 85.8 & 235.85 & 270.16 \\
\hline October & 30.99 & 32.66 & 23.62 & 22.76 & 80.67 & 83.04 & 112.97 & 114.14 \\
\hline November & 28.24 & 30.42 & 18.43 & 17.26 & 74.05 & 72.79 & 5.25 & 10.36 \\
\hline December & 24.68 & 26.9 & 13.91 & 13.04 & 75.32 & 70.84 & 3.33 & 4.92 \\
\hline
\end{tabular}

Fig.1 Overall prevalence of gastrointestinal parasitic infection in sheep of NAZ and RLZ of

West Bengal, India

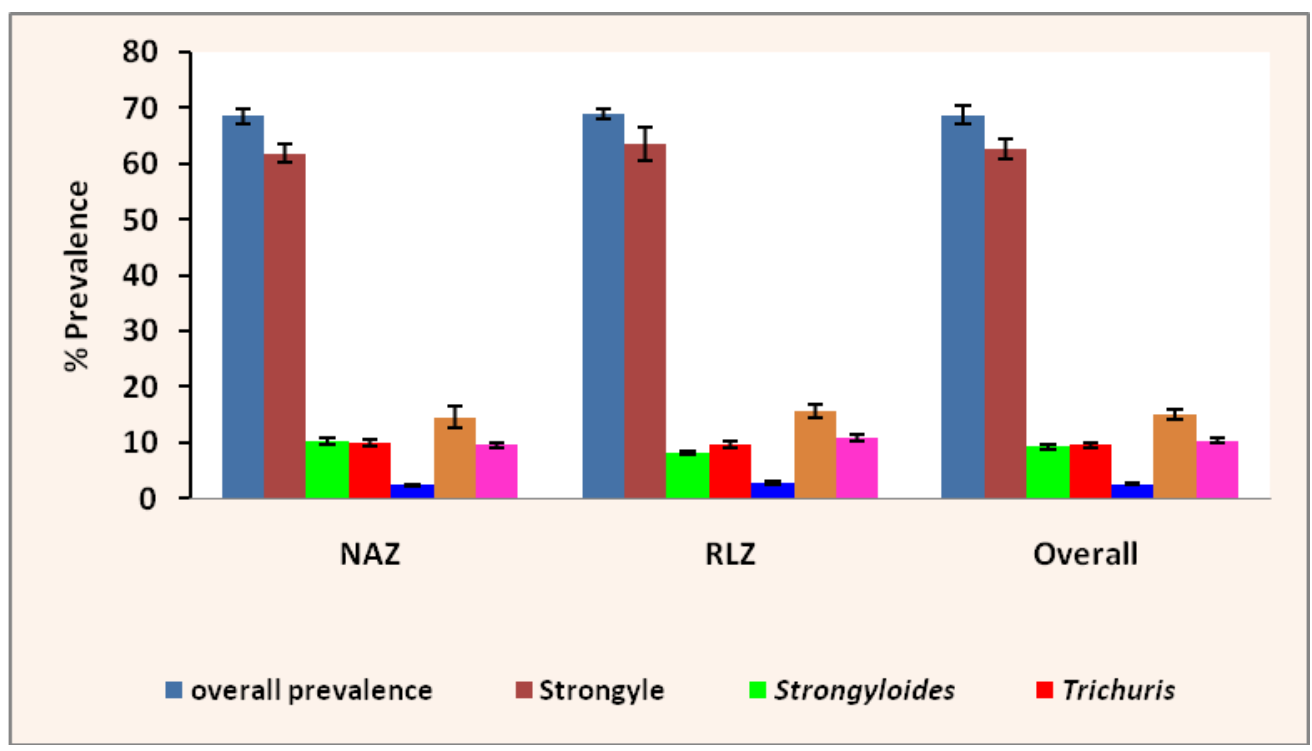


Fig.2 Seasonal prevalence of gastrointestinal parasitic infection in sheep of West Bengal, India

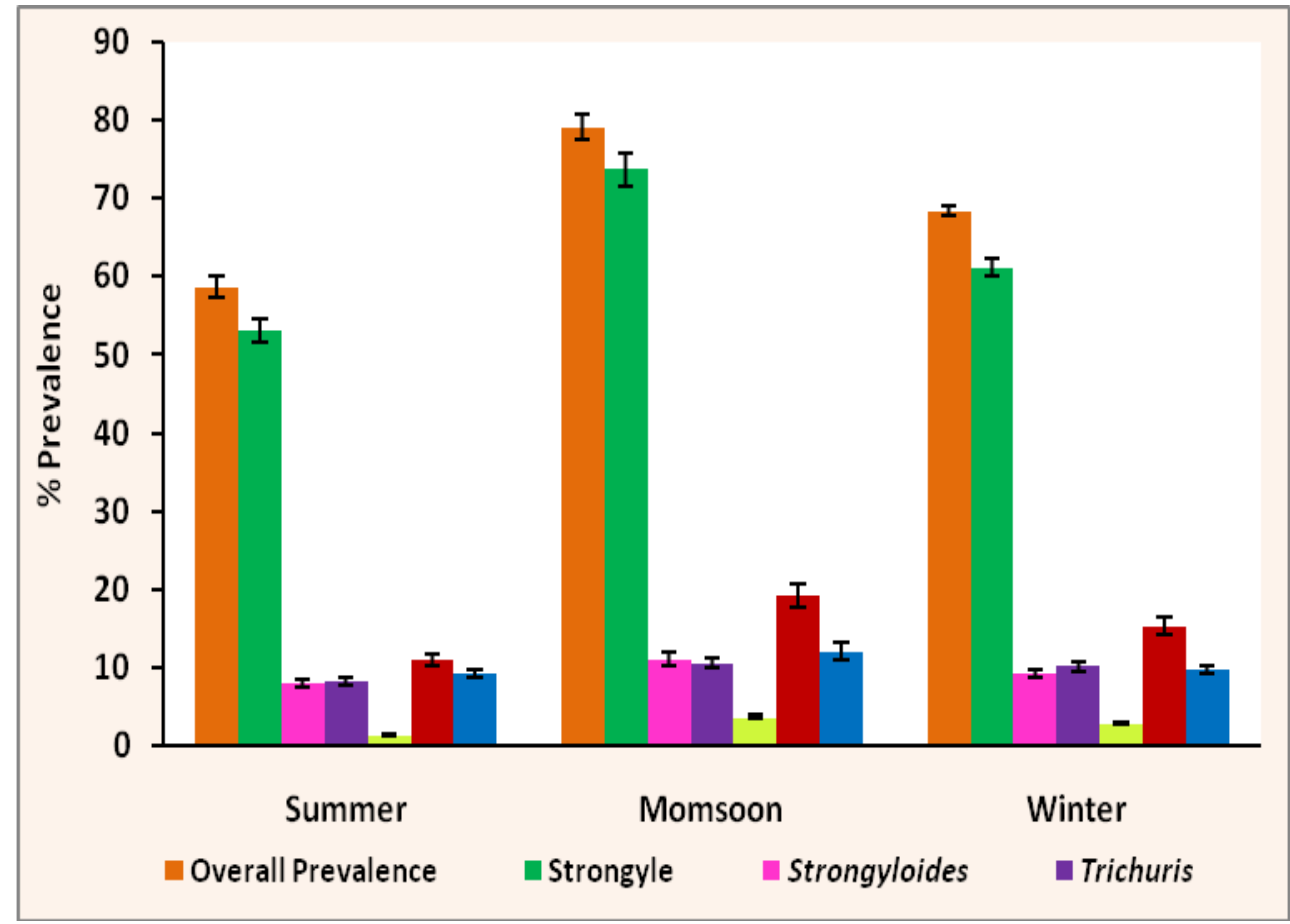

Fig.3 Seasonal prevalence of gastrointestinal parasitic infection in sheep of NAZ of West Bengal, India

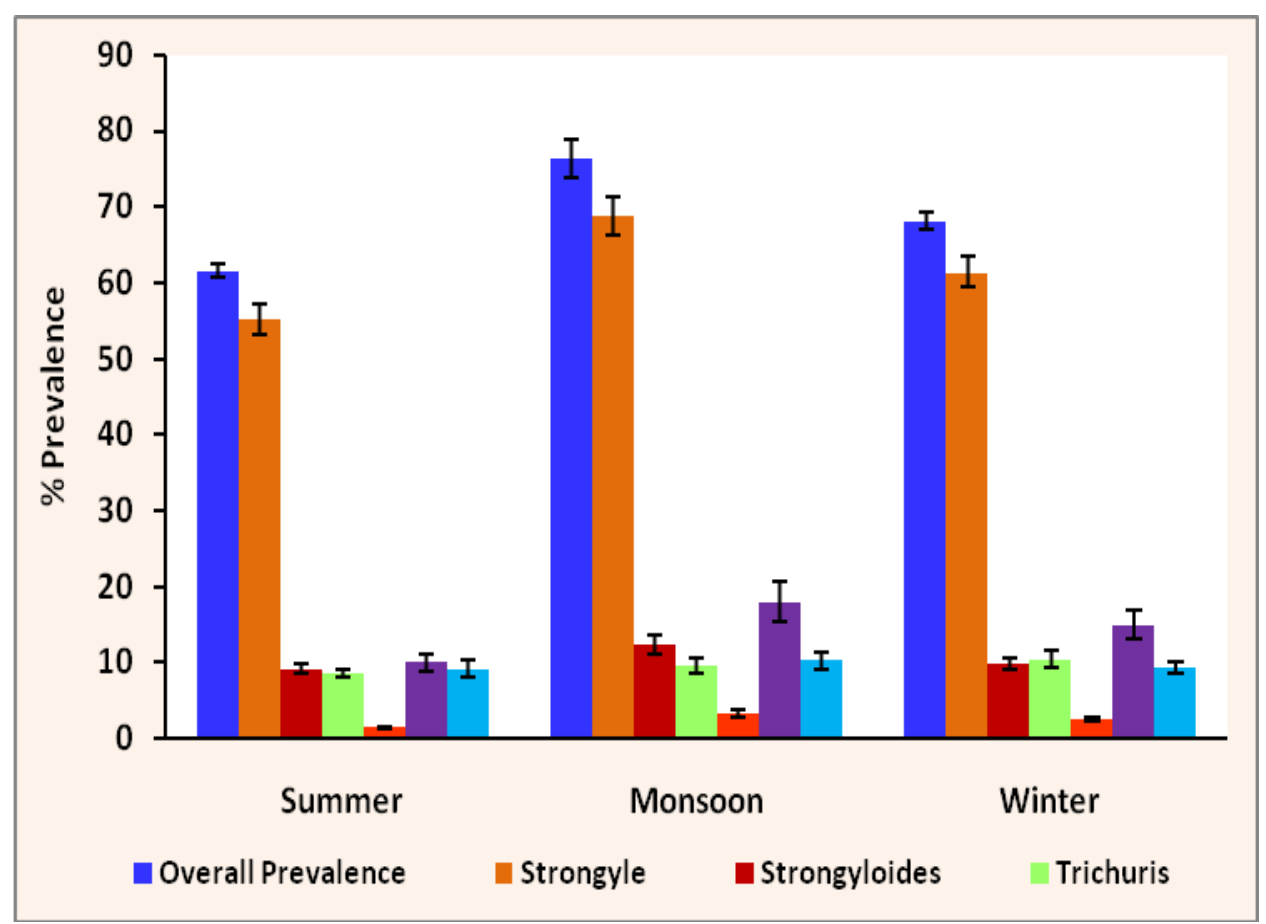


Fig.4 Seasonal prevalence of gastrointestinal parasitic infection in sheep of RLZ of West Bengal, India

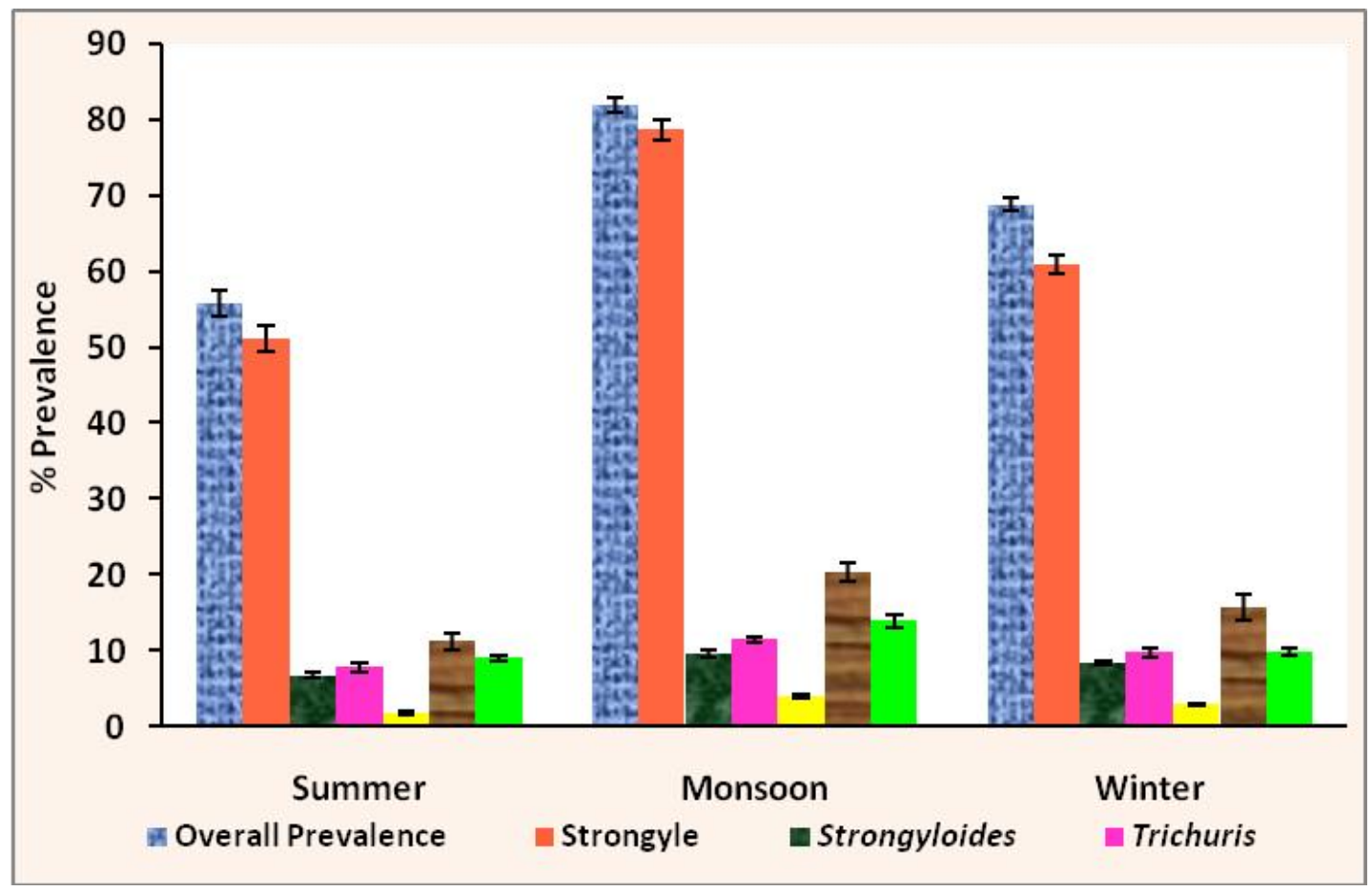

Fig.5 Monthly intensity of gastrointestinal nematode infection in sheep of NAZ and RLZ of West Bengal, India

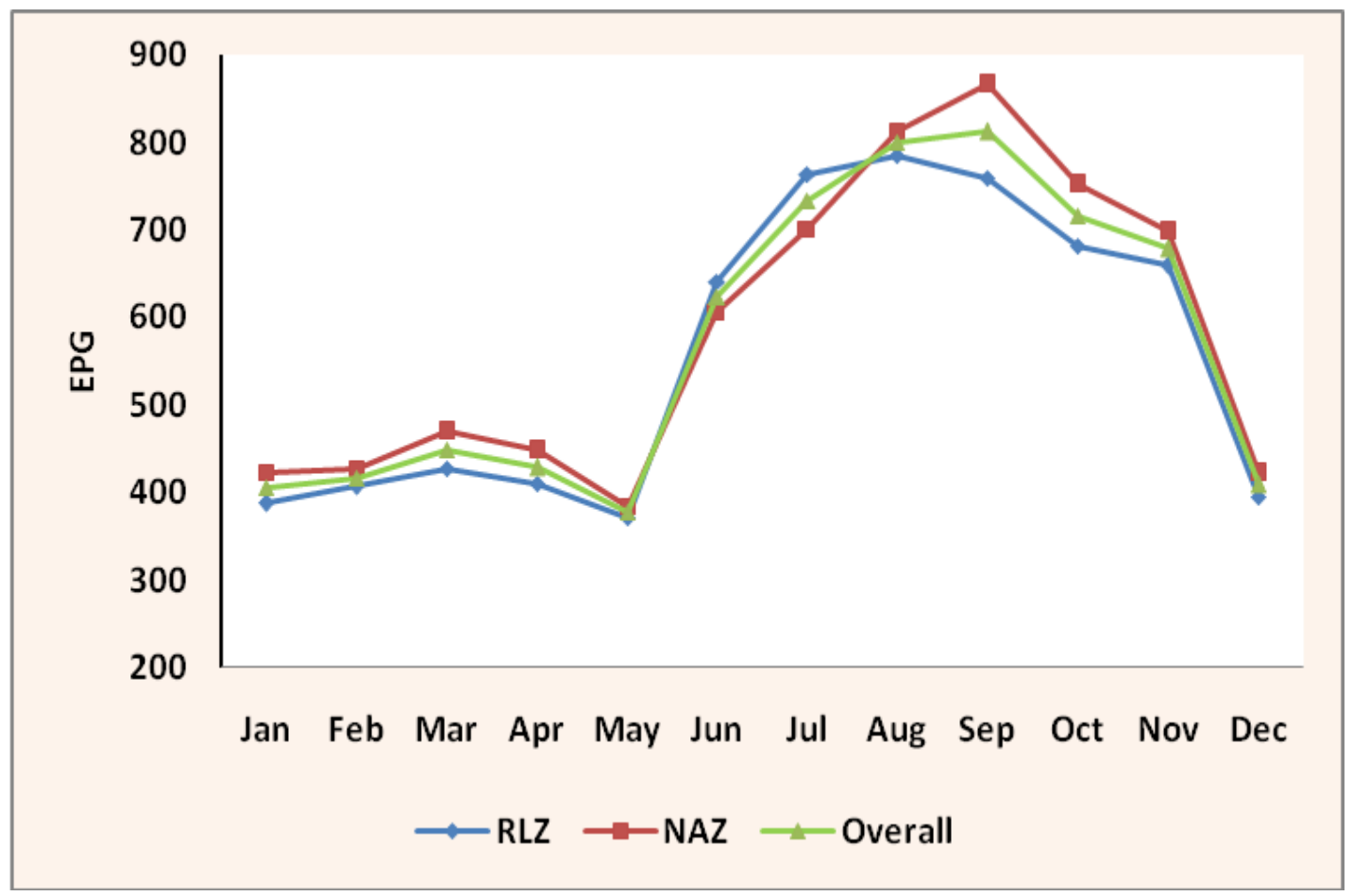


Fig.6 Seasonal intensity of gastrointestinal nematode infection in sheep of NAZ and RLZ of West Bengal, India

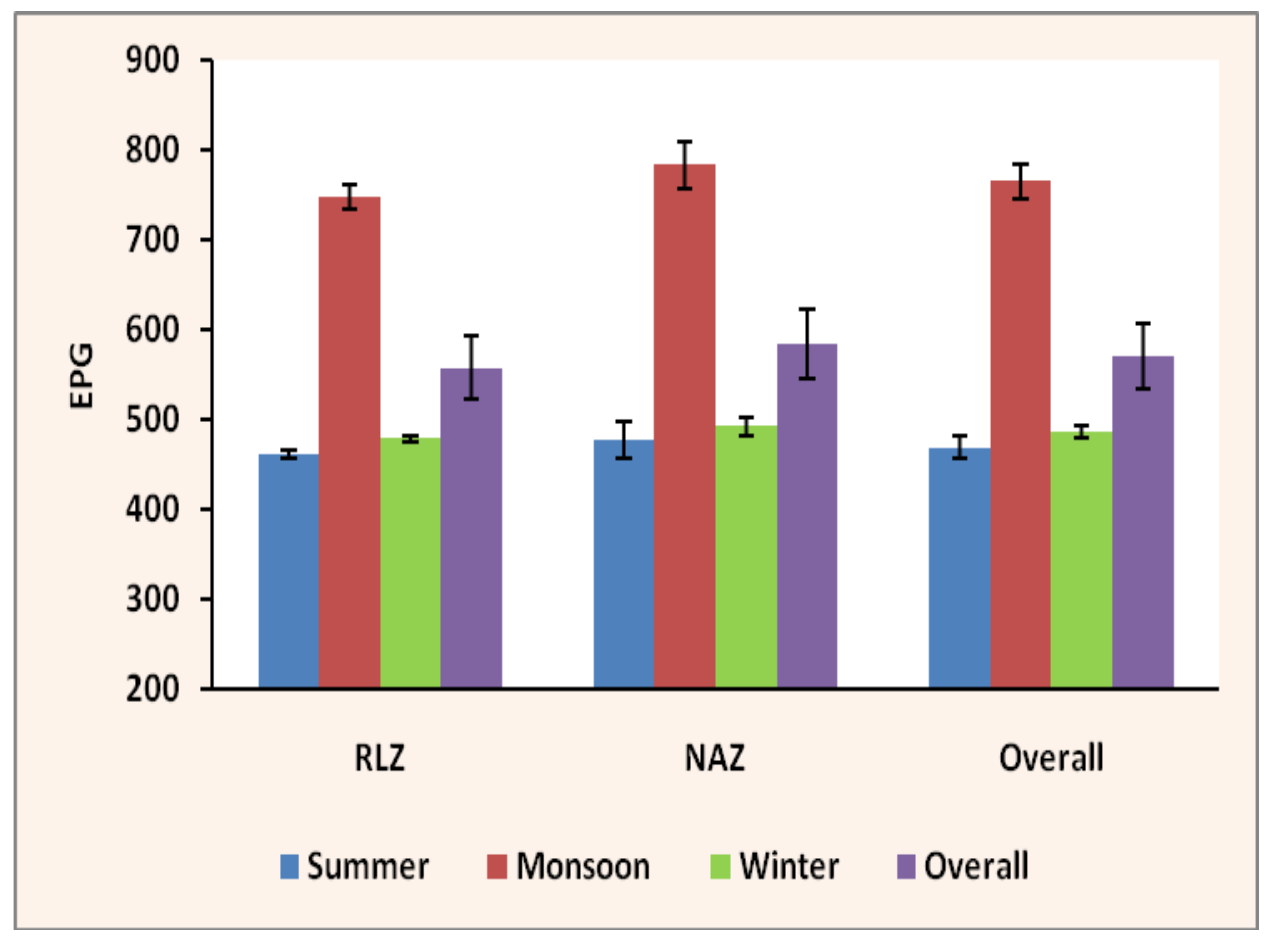

Fig.7 Prevalence of different species gastrointestinal nematode infection in sheep of NAZ and RLZ of West Bengal, India

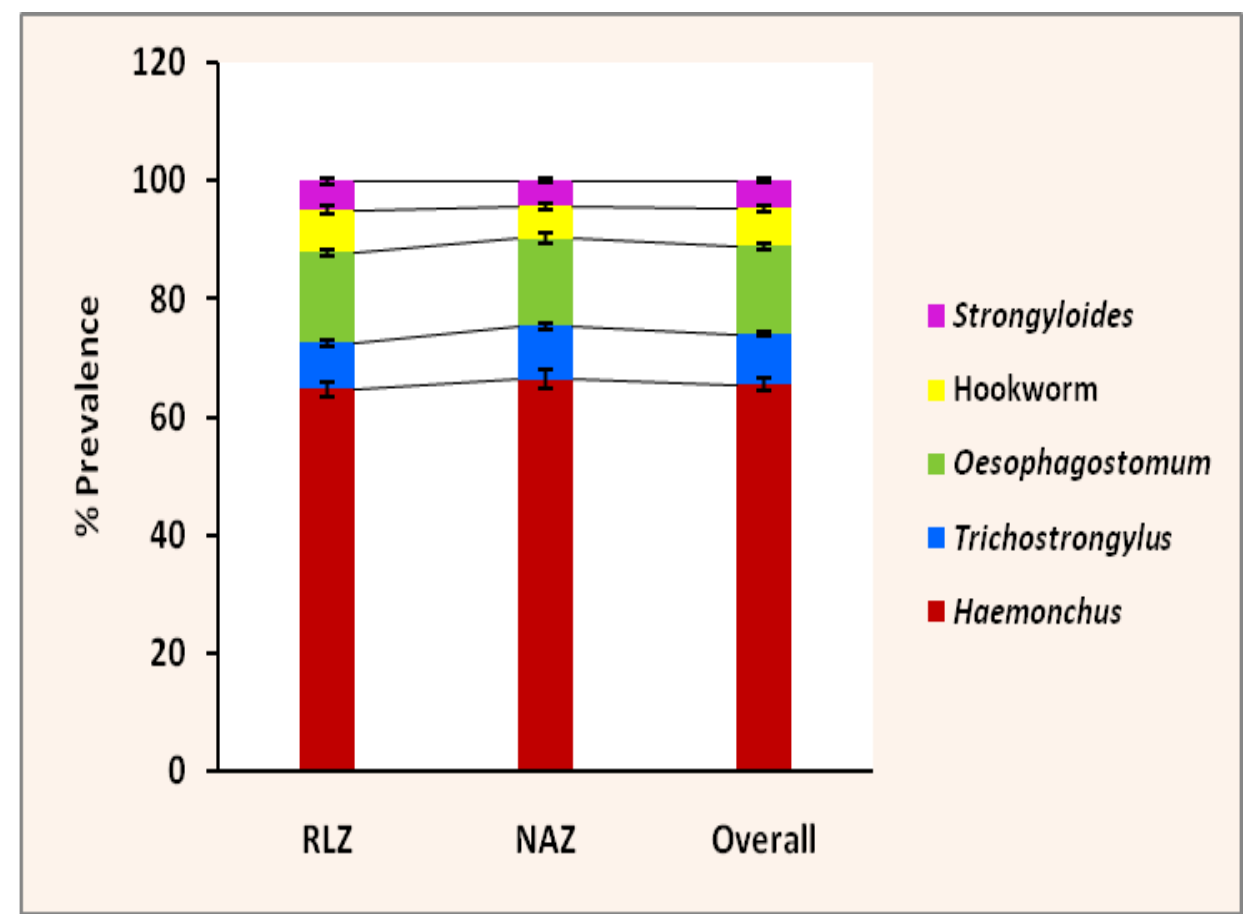


Along with Strongyloides species larvae of four different types of Strongyle group of nematodes viz., Haemonchus, Oesophagostomum, Trichostrongylus and hookworms were found in coprocultural examination. Haemonchus contortus $(65.6 \%)$ was recorded as the predominant g.i. nematode species followed by Oesophagostomum (15\%), Trichostrongylus $(8.4 \%)$, hookworm $(6.4 \%)$ and Strongyloides (4.6\%). The prevalence of Haemonchus and Trichostrongylus was slightly higher in sheep of NAZ (Haemonchus- 66.4\%; Trichostrongylus-9\%) compared to RLZ (Haemonchus- 64.8\%; Trichostrongylus $7.8 \%$ ) of West Bengal (Fig. 7). The prevalence of other three nematode species was slightly higher in sheep of RLZ. These differences between the two agro-climatic zones were not statistically significant $(\mathrm{P}>0.05)$.

\section{Overall prevalence of gastrointestinal helminthes}

Gastrointestinal parasitism dominated by different types of helminths was common occurrence in sheep of NAZ as well as RLZ of West Bengal. Semi-intensive system of rearing and grazing in a common pasture without following routine deworming schedule might be responsible for high incidence of g.i. parasitism in sheep of both the agro-climatic zones of West Bengal, India. Parasitic gastroenteritis is prevalent in sheep throughout the world (Owusu et al., 2016, Leon et al., 2019) including India (Brahma et al., 2018, Singh et al., 2017). The overall prevalence as recorded in the present study was $68.76 \%$ which was much lower than the earlier reports by Singh et al., (2017) and Brahma et al., (2015). Lower rate of prevalence of g.i. helminths in sheep of the present study might be due to the difference in geographical agro-climatic condition of the study location.
No significant difference in prevalence of g.i. helminths was observed between the two agro-climatic zones. This might be due to the fact that the climatic conditions including monthly average temperature, rainfall and relative humidity as per the meteorological observations (Table 1) are more or less similar (AINP, 2016-17) and also the similar sheep rearing practice followed by the farmers of both RLZ and NAZ of West Bengal.

Strongyle group of nematodes was recorded as the predominant species of sheep in the RLZ (63.57\%) and NAZ (61.91\%). Similar findings have also been reported earlier (Brahma et al., 2018, Jas et al., 2017). Temperature ranging from $18^{\circ}-37^{\circ} \mathrm{C}$ and a relative humidity above $50 \%$ or monthly total rainfall about $50 \mathrm{~mm}$ are required for development and survival and translation of larvae of Strongyle group of nematodes in pasture ( Singh et al., 2011).

The climatic condition as stated above prevails all-round the year (Table 1) except for few months and this might be responsible for highest prevalence of Strongyle group of nematodes. In present study about $15 \%$ of sheep of both NAZ and RLZ showed infection with Paramphistome and this might be due to grazing in and around the water logged area which are plenty in West Bengal.

In both the zones number of ponds and irrigation channels in the agricultural fields favours the breeding and survivality of snail population which might be responsible for prevalence of Paramphistome infection in sheep (Singh et al., 2011) and Moniezia sp. infection was recorded in $10.38 \%$ of sheep examined in both the agro-climatic zones during the study period and this is in agreement with earlier report (Brahma et al., 2018). 
Season-wise prevalence and intensity of Strongyle group of nematode infection

The prevalence of g.i. helminth parasites and the intensity of Strongyle group of nematodes differed significantly $(\mathrm{P}<0.05) \quad$ during different seasons in sheep of both RLZ and NAZ. In both the zones the prevalence as well as intensity of g.i. helminth infection was significantly $(\mathrm{P}<0.05)$ higher during monsoon compared to summer and winter. The seasonal variation of g.i. helminths as observed in the present study has also been reported earlier by many authors (Brahma et al., 2018, Ghosh et al., 2012). In both the zones of West Bengal, the climatic conditions like monthly maximum and minimum temperature and relative humidity during monsoon season are more or less similar (AINP, 2016-17) and these climatic conditions are most favourable for development and survival of free living stages of nematode parasites and also favourable for breeding of snail intermediate host for Paramphistomes. Therefore the prevalence as well as the intensity of g.i. nematode infections were highest during the monsoon compared to other two seasons. In winter months low temperature and less amount of rainfall also the low humidity and in summer months higher temperature and low rainfall and drying up of ponds or small water channels might be the reason for lower rate of prevalence and intensity of g.i. parasites in sheep.

The prevalence of g. i. helminths was significantly $(\mathrm{P}<0.05)$ lower in sheep of RLZ compared to NAZ during the summer season. This lower prevalence in RLZ during the summer months might be due to slightly higher environmental temperature and low humidity (Table - 1) which were not favourable of survival and translation of parasitic larvae in the pasture whereas in the NAZ the temperature and relative humidity were in the favourable range (AINP, 201617).

\section{Prevalence of different species of Strongyle nematodes}

Haemonchus contortus, as revealed in Coprocultural examination, was found to be the most prevalent species of g. i. nematode of sheep of both the agro-climatic zones of West Bengal. Haemonchus contortus has been recorded earlier as the predominant nematode species infecting sheep and goats of India including West Bengal (Jas et al., 2017, Pathak and Pal, 2008, Singh et al., 2013). Favourable climatic condition for the development and survival of infective third stage larvae of $H$. contortus (Jas et al., 2017) are observed all round the year of RLZ and NAZ. Along with the favourable environmental condition availability of green grasses and common grazing area for sheep and goats in both the zones might be responsible for higher prevalence of $H$. contortus. Besides H. contortus other pathogenic g. i. nematodes such as Oesophagostomum, Trichostrongylus and hookworms were also recorded in sheep of both the agro-climatic zones.

In conclusion, there was no significant $(\mathrm{P}<0.05)$ difference in overall prevalence and intensity of $\mathrm{g}$. i. helminthic infection between the sheep of RLZ and NAZ of West Bengal.

The prevalence pattern of Haemonchus contortus and Paramphistomes, two important g.i. helminths of small ruminants, and the climatic conditions are more or less similar in both the agro-climatic zones of West Bengal. Therefore a common strategic worm control programme based on the epidemiological data compiled in the present study can be adopted for the sheep of NAZ and RLZ, West Bengal, India. 


\section{Acknowledgement}

The authors thankfully acknowledge Late Prof. J. D. Ghosh and the financial assistance of the Indian Council of Agricultural Research, New Delhi in conducting this study under the research project entitled "All India Network Programme on Gastrointestinal Parasitism.”

\section{References}

Adzitey, F., 2013. Animal and meat production in Ghana - An overview. J. World's Poult. Res. 3, $1-4$.

AINP Report. 2016-2017. Annual progress report, all India network programme on gastrointestinal parasitism. New Delhi: Kolkata Centre, Indian Council of Agricultural Research.

Brahma, A., Das, S., Kumar, D., Bordoloi, G., Pandit, S., Bera, S., Ghosh, J.D. and Jas, R. 2015. Prevalence of gastrointestinal parasites in Black Bengal goats of Sundarban delta in West Bengal. Int. J. Parasitol. Res. 7, 156 - 159.

Brahma, A., Jas, R., Das, S. and Ghosh, J.D. 2018. Prevalence of Gastrointestinal Helminth Infection in Garole Sheep of Sundarban Delta in West Bengal. J. Anim. Res. 8(1), 57 - 60.

Fikru, R., Teshale, S., Reta, D. and Yosef, K. 2006. Epidemiology of gastrointestinal parasites of ruminants in Western Oromia, Ethiopia. J. Appl. Res. Vet. Med. 4(1), $51-57$.

Ghosh, J.D., Jas, R. and Bordoloi, G. 2012. Exploration of resistance/resilience against gastrointestinal nematode infection in Garole sheep. Ind. J. Anim. Sci. $82,818-821$.

HSMO (Her Majesty's Stationery Office). 1971. Manual of veterinary parasitological laboratory techniques. London: Ministry of Agriculture, Fisher-ies and Food, Technical Bulletin
No 18.

Ibrahim, N., Tefera, M., Bekele, M. and Alemu, S. 2014. Prevalence of gastrointestinal parasites of small ruminants in and around Jimma Town Western Ethiopia. Acta. Parasitol. 5, 26 -32 .

Jas, R. and Ghosh, J.D. 2009. Economic impact of gastrointestinal nematodosis in sheep: enhanced meat production by anthelmintic treatment. Ind. J. Anim. Sci. 79, $3-5$.

Jas, R., Ghosh, J.D., Pandit, S., Kumar, D., Brahma, A., Das, S., Das, M. and Ralte, L. 2017. Economic impact of gastrointestinal nematodosis in terms of meat production in small ruminants of West Bengal. Int. J. Microbiol. Res. 9(1), $834-836$.

Jas, R., Kumar, D., Bhandari, A. and Pandit, S. 2017. Seasonal alteration in prevalence and intensity of naturally occurring gastrointestinal helminths infection in goats of New Alluvial zone of West Bengal, India. Biol. Rhyth. Res., 48(6), $867-876$.

Leon, J.C.P., Delgado, U.N. and Florez, A.A. 2019. Prevalence of gastrointestinal parasites in cattle and sheep in three municipalities in the Colombian Northeastern Mountain. Vet. World. 12 (1), $48-54$.

Odoi. A., Gathuma, J.M., Gachuiri, C.K. and Omore, A. 2007. Risk factors of gastrointestinal nematode parasite infections in small ruminants kept in smallholder mixed farms in Kenya. BMC Vet. Res. 3, 6

Owusu, M., Sekyere, J.O. and Adzitey, F. 2016. Prevalence and burden of gastrointestinal parasites of Djallonke sheep in Ayeduase, Kumasi, Ghana. Vet. World. 9(4), $361-364$.

Pathak, A.K. and Pal, S. 2008. Seasonal prevalence of gastrointestinal parasites in goats from Durg district of 
Chhattisgarh. Vet. World. 1(5), $136-$ 137.

Singh, D., Swarnkar, C.P., Prince, L.L.L. and Pathak, K.M.L. 2011. Economic analysis and impact of gastrointestinal nematodes on sheep production in Rajasthan. Directorate of Knowledge Management in Agriculture. Indian Council of Agricultural Research, New Delhi, India.

Singh, E., Kaur, P., Singla, D. and Bal, M.S. 2017. Prevalence of gastrointestinal parasitism in small ruminants in western zone of Punjab, India. Vet. World. 10(1), $61-66$.

Singh, V., Varshney, P., Dash, S.K. and Lal, H.P. 2013. Prevalence of gastrointestinal parasites in sheep and goats in and around Mathura. Vet. World. 6, $260-262$.

Soulsby, E.J.L., 1982. Helminths, arthropods and protozoa of domesticated animals. 7th ed. London: The English Language Book Society and Ballière Tindall.

\section{How to cite this article:}

Ruma Jas, Dhananjay Kumar, Soumitra Pandit, Anupam Brahma and Surajit Baidya. 2020. Cross-sectional Study on Prevalence of Gastrointestinal Parasitic Infection in Sheep: Comparative Analysis between Agro-climatic Zones of West Bengal, India. Int.J.Curr.Microbiol.App.Sci. 9(01): 1570-1581. doi: https://doi.org/10.20546/ijcmas.2020.901.174 